\title{
Informações seguras sobre a pandemia de Covid-19
}

DOI: dx.doi.org/10.18616/nrm01

Fabiane Ferraz

Felipe Pedroso

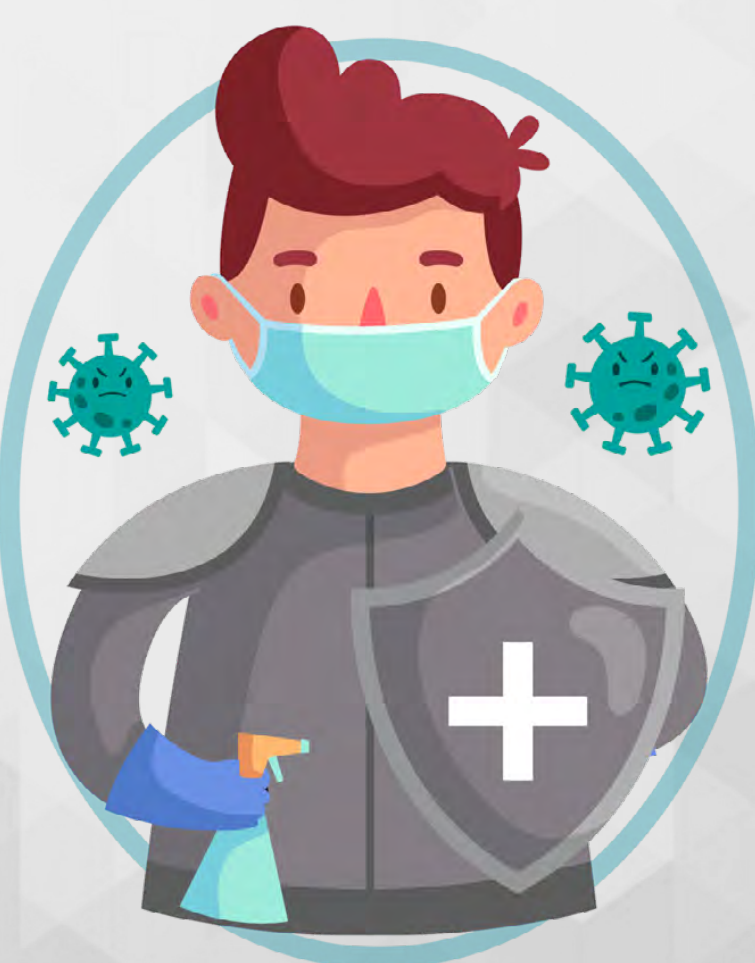




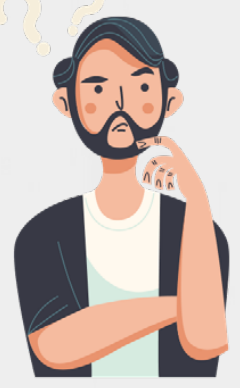

Em nenhum outro tempo, as pessoas tiveram tantas oportunidades de acesso a informações como atualmente. Contudo, o maior desafio enfrentado por todos nós é selecionarmos qual informação é confiável.

Em meio a uma "enxurrada" de notícias que recebemos todos os dias, como nos certificarmos de que o que estamos lendo e/ou assistindo e, principalmente, o que estamos compartilhando em nossas redes sociais é VERDADEIRO?

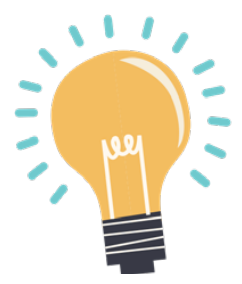

DICA: Sempre que uma informação causar em você grande espanto, ou preocupação, ou sentimentos como raiva e medo, ou indignação, ou for algo que promete ganhos financeiros ou pessoais fáceis, NUNCA repasse essa informação antes de buscar locais que possam comprovar se ela é verdadeira!

Precisamos nos questionar: “Eu gosto de ser enganado?". Se nossa resposta for "NÃO!", então o que nos cabe atualmente é sermos muito cuidadosos com informações que iremos repassar às outras pessoas, pois, afinal, não devemos fazer a elas o que não gostaríamos que fizessem conosco!

Nesse sentido, é essencial termos certeza de que o que estamos compartilhando em nossas redes sociais não se trata de Fake News (notícias falsas), em especial neste momento que estamos vivendo, relacionado à Covid-19, pois notícias falsas sobre essa doença específica, bem como sobre qualquer FAKE NEWS aspecto relacionado à saúde ou a outras doenças podem ser extremamente prejudiciais a todas as pessoas. 


\section{IMPORTANTE SABERMOS!}

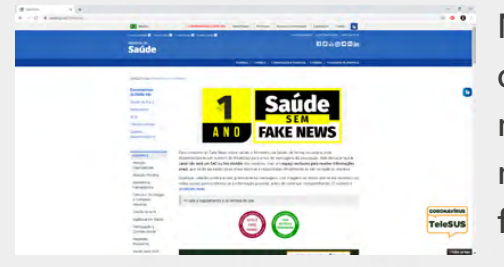

No Brasil, o Ministério da Saúde, em 2019, a fim de combater notícias falsas na saúde, criou um modo de confirmar se a notícia é verdadeira ou não. Você pode acessar esse espaço de duas

rimasus formas:

Acesse o Site

Em relação à Covid-19, já há um espaço exclusivo nesse site que nos permite conferir o que já foi diagnosticado como Fake News: https://www. saude.gov.br/component/tags/tag/novo-coronavirus-fake-news.

Qualquer cidadão pode enviar, gratuitamente, mensagens com imagens ou textos que tenha recebido nas redes sociais para confirmar se as informações procedem antes de continuar compartilhando-as.

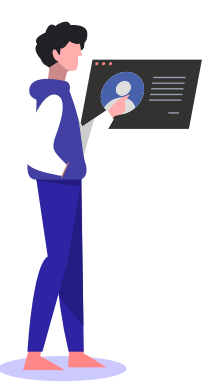

O número do telefone é (61) 9.9289.4640.

- Horário de atendimento: de $2^{\mathrm{a}}$ a $6^{\mathrm{a}}$-feira (exceto nos feriados), das $10 \mathrm{~h} 30$ às $12 \mathrm{~h}$ e das $14 \mathrm{~h}$ às $18 \mathrm{~h}$ (horário de Brasília-DF).

- Fluxo de atendimento:

$A(O)$ cidadã(o) envia a mensagem sobre saúde que recebeu e que deseja confirmar se é verdadeira ou falsa. A mensagem deverá conter:

1. Nome completo;

2. Município e Estado de residência;

3. Mensagem que deseja averiguar.

Para mais informações, acessar o termo de uso:

Termo de uso

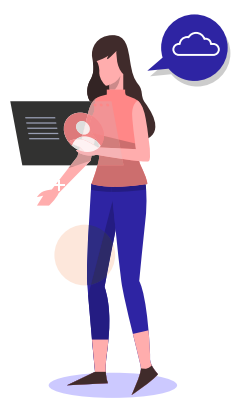


Com a intenção de auxiliá-lo(a) no acesso a informações confiáveis, seguem algumas indicações de espaços que possuem materiais tanto para profissionais da saúde quanto para a população em geral:

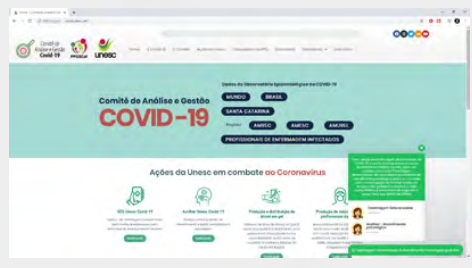

Site da Universidade do Extremo Sul Catarinense - UNESC com informações e serviços de atenção à saúde disponibilizados pela Universidade.

Acesse o Site

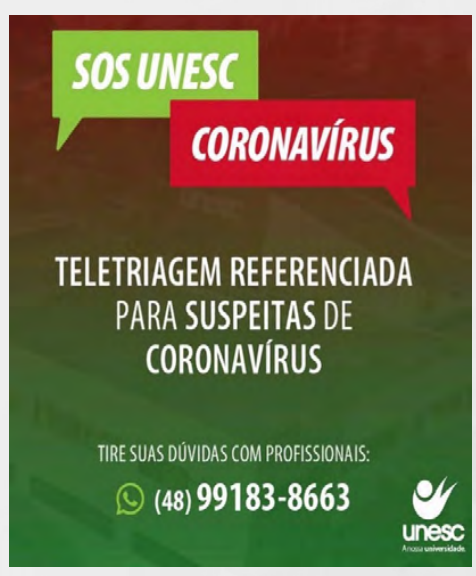

SOS-COVID-19 - Serviço disponibilizado pela UNESC para realizar, via WhatsApp o primeiro atendimento às pessoas que apresentam dúvidas e, com isso, diminuir o número de indivíduos expostos nos serviços de saúde

O número oficial para os atendimentos é o (48) 9.9183 .8663$.

O serviço atende de segunda a sexta-feira, das $8 \mathrm{~h}$ às $20 \mathrm{~h}$.

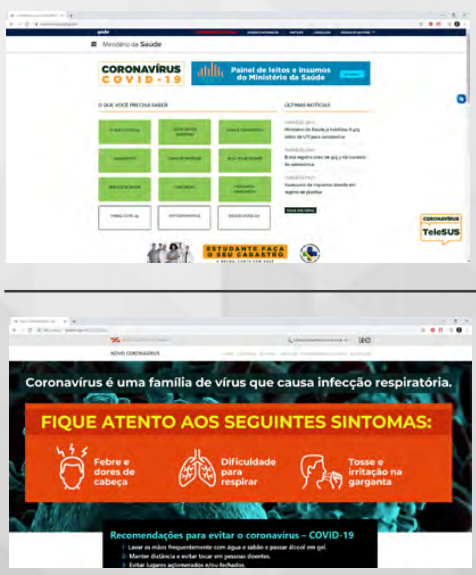

Site do Ministério da Saúde com informações sobre o Coronavírus (SARS-CoV-2) e a Covid-19.

Acesse o Site

Site da Secretaria do Estado da Saúde de Santa Catarina com informações sobre o Coronavírus e a Covid-19. 


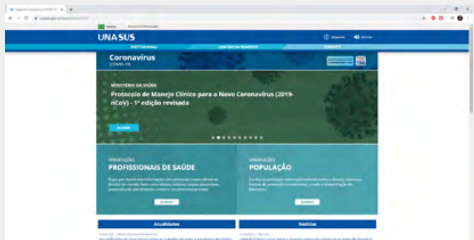

A Universidade Aberta do SUS (UNA-SUS) possui um site especial relacionado à Covid-19, no qual você encontra informações tanto para profissionais da saúde quanto para a população em geral.

Acesse o Site

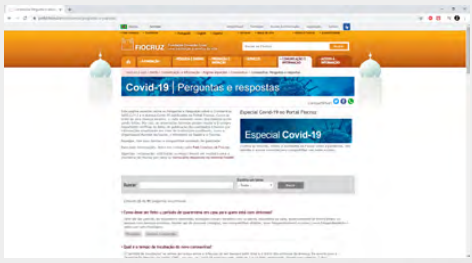

Esta página especial reúne as Perguntas e as Respostas sobre o Coronavírus (SARSCoV-2) e a doença Covid-19, publicadas no Portal Fiocruz.

Acesse o Site

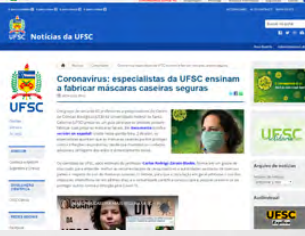

A Universidade Federal de Santa Catarina (UFSC) lançou um informativo que explica como a população pode confeccionar máscaras caseiras seguras.

Acesse o Site

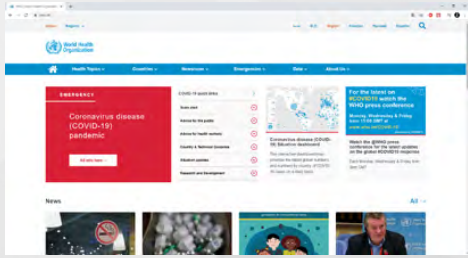

Site da Organização Mundial da Saúde.

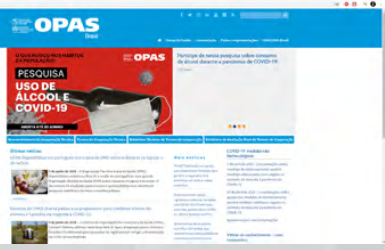

A Organização Pan-Americana da Saúde tem distintos sites, conforme os países membros. Você poderá encontrar informações sobre a Covid-19 nos links a seguir: 


\section{ATENÇÃO!}

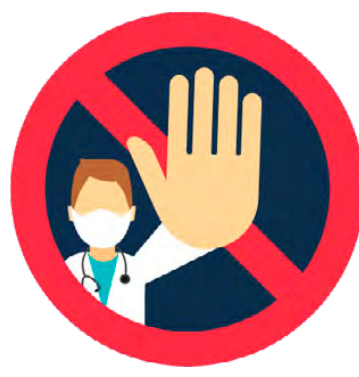

A OPAS/OMS alerta que NÃO está solicitando informações à população com promessas de entrega de recursos financeiros ou de outros benefícios. Caso você receba e-mail ou mensagens em redes sociais, é uma FRAUDE! Portanto, não passe nenhum dado pessoal!

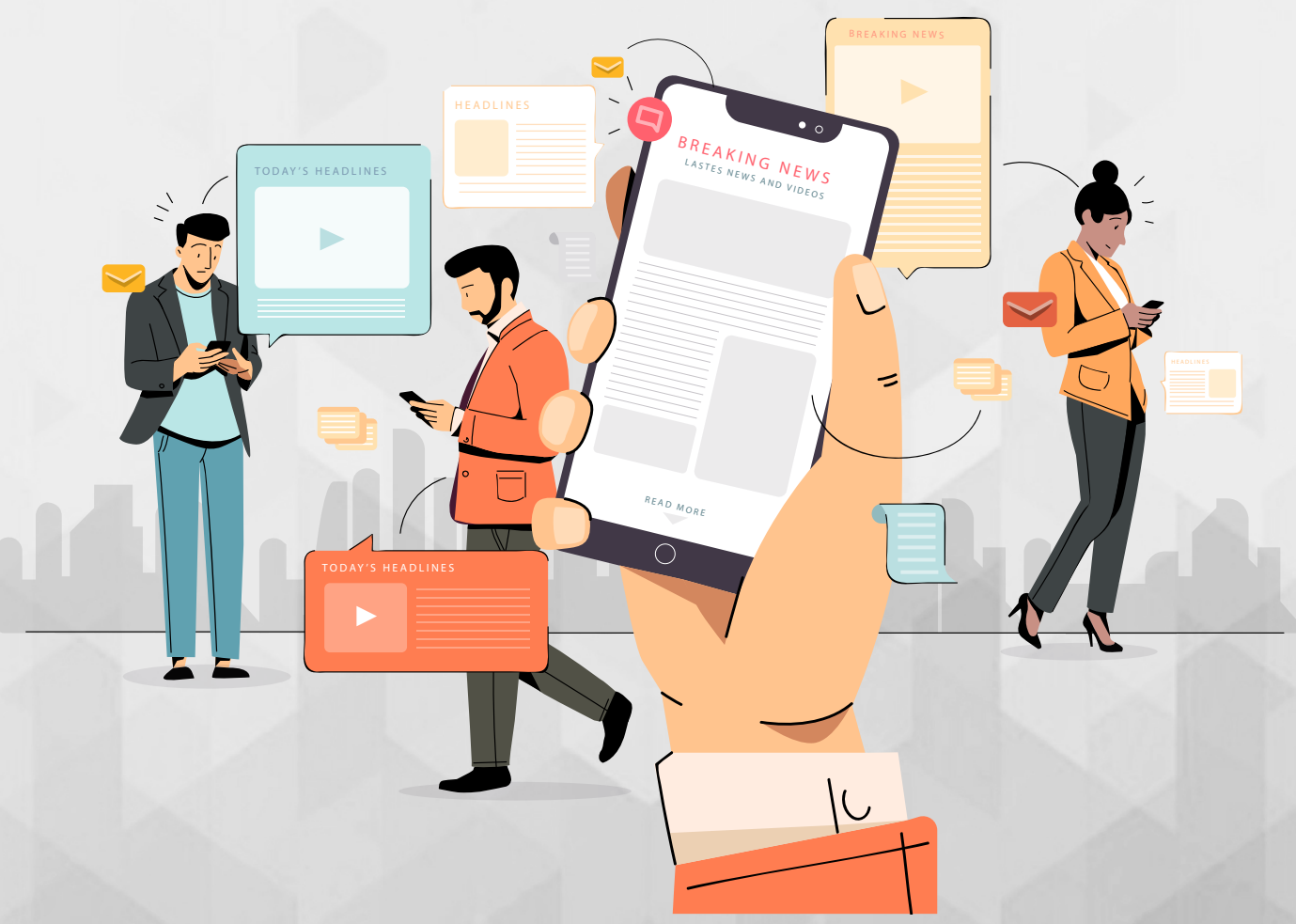




\section{PARA REFLEXÃO}

Atualmente, é muito importante usarmos, mais do que nunca, um grande ensinamento "atribuído" a Sócrates, denominado "As Três Peneiras da Sabedoria".

Contam que...

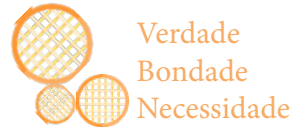

Um rapaz procurou Sócrates e disse-lhe que precisava contar algo sobre alguém. Sócrates olhou para o rapaz e perguntou:

- O que você vai me contar já passou pelas três peneiras?

- Três peneiras? - indagou o rapaz.

- Sim! A primeira peneira é a VERDADE. O que você quer me contar dos outros é um fato? Caso tenha ouvido falar, mas não tem certeza da sua veracidade, a coisa deve morrer aqui mesmo.

- Suponhamos que seja verdade. Deve, então, passar pela segunda peneira: a BONDADE. O que você vai contar é uma coisa boa? Ajuda a construir ou destruir o caminho, a fama do próximo?

- Se o que você quer contar é verdade e é coisa boa, deverá passar ainda pela terceira peneira: a NECESSIDADE. Convém contar? Resolve alguma coisa? Ajuda a comunidade? Pode melhorar o planeta?

Arremata Sócrates:

- Se passou pelas três peneiras, conte! Tanto eu como você iremos nos beneficiar. Caso contrário, esqueça e enterre tudo!

Fonte: Beck (2017).

Acesse o Link

Cabe expressar que mesmo não havendo certeza absoluta da autoria da parábola citada, o mais importante, neste momento, é a reflexão que ela nos possibilita (Para saber mais, ler "O paradoxo das três peneiras de Sócrates”, em Natrieli (2016). Acesse o link

Acesse o Link 